There has recently been published a fresh determination of the position of Sabine Island on the coast of north-east Greenland which tends to show that there is a definite westerly drift of some metres a year. Similar observations of Jan Mayen are even more startling. For these and other reasons, therefore, the geophysicist, whom we may call the mathematical cousin of the geologist, must keep his attention on the polar lands.

In the biological sciences also there are major problems to which the data of high latitudes alone can give the key, such as the drift of oceanic waters and the movements of plankton and their associated salts. The biologists, however, are already active in these investigations and need no spur to action. The many-sided character of the work of the "Discovery" Committee in this branch, over all the waters of the Antarctic ocean, is evidence of how carefully work on this aspect of the polar regions is being carried out.

\section{The Spirit of Exploration}

Lastly, I would consider yet another aspect of the polar regions, one which is perhaps more psychological than geographical, namely, their value as an outlet to that spirit of adventure and urge for exploration which has always been an attribute of man, and which will not diminish, however small the world may grow. It is a spirit which is at work equally in the small child climbing the apple tree, the schoolboy exploring his own small horizon, the undergraduate forming alpine clubs to scale the peaks of his own college, and the city clerk spending his week-ends living dangerously in sailing dinghy or on motor-bicycle.

In all of these there is a curious combination of an urge to test one's abilities and yet a desire for a secondary and more useful object in the deed itself, and this dual purpose is particularly evident in most of the young men who come to the Scott Polar Research Institute in Cambridge seeking ways in which to visit the Arctic.

Looking over the files of the geographical journals of the past few years, it is possible to see how many young men turn annually to the Arctic to satisfy their need for an outlet. If we include the official expeditions of Governments such as that of the Soviet, we shall find that every summer more than fifty groups of investigators go to the Arctic and, were it less expensive, the number would easily be trebled. Only a few of these groups go for purely scientific work, and still fewer for hunting alone. They are, in fact, as a rule imbued chiefly with a desire to see strange places and endure strange things, and only in a secondary way to bring back useful results. There has been of recent years a happy tendency for these groups to go and come back without undue fuss and publicity. I would suggest that this use of the Arctic as an outlet to a healthy and laudable desire is one which should not be left out of any assessment of values even though it must necessarily apply only to a small number of people.

\title{
Problems of Plant Pathology
}

$\mathrm{T}$ HE presidential address of Mr. F. T. Brooks to Section K (Botany) of the British Association delivered at Norwich on September 9 began in very pleasing vein by describing some of the outstanding contributions to botany made in East Anglia, wherein Norwich is an ancient and important city. It is fitting that upon such an auspicious occasion, the president of the Section should remind his audience of the deep roots of botanical lore in Great Britain-roots which go back to the enthusiasm of the ardent amateur. One heard the names of W. H. Burrell, W. A. Nicholson and Dr. C. B. Plowright coupled, in the recital of botanical progress in Norfolk, with more professional workers such as Dr. M. C. Cooke, Sir W. J. Hooker, Prof. F. W. Oliver, Prof. E. J. Salisbury, and many others.

The title of the address was "Some Aspects of Plant Pathology", and after showing that Norfolk farmers were among the first to realise the damage caused by disease, Mr. Brooks continued with a discussion of disease control by the use of resistant varieties of crop plants. The bad effects of several wilt diseases, the leaf-curl disease of cotton, and black rust of wheat can now be controlled with considerable success by planting new varieties with resistant qualities, but it seems very unlikely that all diseases will be amenable to control by this method. New diseases are continually appearing, parasitic fungi are amongst the most variable of living organisms, and the capacity for disease resistance in the host is very much in the nature of a mutation. The nicelyadjusted equilibrium between parasite and host can be upset when the latter mutates towards resistance, but the fungus can also vary, to give a new physiological form capable of attacking the host mutant. Thus the biological race for 
supremacy continues, and leads the plant pathologist to investigate further principles of control. Moreover, although the use of resistant host varieties is the most care-free method of disease control, it is not always the most efficacious. Bunt in wheat, for example, may be totally eliminated by simple fungicidal treatment of the seed before sowing, and infection of fruit trees with Stereum purpureum can be greatly minimised if the fungus is merely prevented from fructifying in and near the orchard. Such simple methods of plant hygiene should be part of the routine of every good gardener or farmer.

The ecological study of fungi is in its infancy, but the effect of climate on some diseases has been investigated. Prof. L. R. Jones and his colleagues at the Department of Plant Pathology, University of Wisconsin, have inquired into the effect of soil temperature upon disease incidence. Such parasites as Urocystis cepulae, for example, cannot infect the onion plant when the soil temperature rises above $29^{\circ}$ C. ${ }^{1}$. Reinking ${ }^{2}$ has shown that differing types of soil may play a controlling part in fungal attack, for the wilt disease of bananas in Central America is much more severe on sandy soils than on clay. High humidity may also inhibit parasitic attack, for the pink disease of rubber in Malaya only appears in the regions of highest rainfall. It seems likely that in the near future it may be possible, by studying weather conditions, to advise growers of the appropriate times to spray potatoes and vines with protective fungicides against blight (Phytophthora infestans) and downy mildew (Plasmopara viticola) respectively. Such treatment, if performed thoroughly and as a matter of routine by all growers would, in all probability, entirely prevent the development of either disease.

The physiology of parasitism is now fairly well understood. The Tulasne brothers, de Bary, Brefeld, and Marshall Ward carried out much pioneer work, and the subject has been further interpreted by Prof. V. H. Blackman in more recent years. Mr. Brooks himself, in his specialist work on Stereum purpureum, has shown that the characteristic silvering of fruit tree foliage can be produced by injecting the stem of a healthy plant with non-living extracts of the fungus.

Our ancestors must have felt despondent and impotent when a sudden attack of black rust spread amongst their wheat, or when blight devastated their potatoes. We can scarcely wonder that they used the term 'magic' to account for such epidemics. Yet the glamour of magic is far surpassed by the fascinating results of investigations into the cause of such apparently spontaneous outbreaks. Mr. Brooks chose a sufficiently sensational example from the work of Mehta $^{3}$ in the lowlands of northern India. Uredo- spores of the fungus Puccinia graminis cannot withstand the very high temperatures of the plains in summer, yet the parasite appears year after year. The usual alternative host, Berberis vulgaris, here plays no part in the life-history. Infection comes each year from stray wheat plants growing above a height of $4,000 \mathrm{ft}$. in the Himalayas. Summer temperatures there are relatively moderate, and uredospores multiply normally, infecting the wheat crop of the hills during November and December. There is thus a continual source of spores, some of which are carried many hundreds of miles to the plains, by the prevailing north. westerly winds.

Research into physiological forms of parasitic fungi has been very active during the past ten years. More than a hundred such forms of Puccinia graminis are now known. The structure of each form is identical with that of all its fellows, but its host relations are different. Many other species of fungi have numerous physiological or biological forms, and it is obvious that the plant breeder is confronted by a very difficult task in his search for new host varieties which would be disease-resistant. The range of physiological forms does not seem to be standard, for types of Puccinia triticina and $P$. glumarum have been found at Cambridge, which do not appear on the Continent, and vice versa. This multiplicity of strains may even include non-pathogenic forms, as happens in the fungus Fusarium cubense, causing wilt disease of the banana ${ }^{4}$. Physiological forms may have arisen as a result of hybridisation, but some must also have arisen as gene mutants, since they appear in fungi such as Puccinia glumarum which are now, in all probability, entirely asexual. $\mathrm{Mr}$. Brooks discountenances the idea of a 'bridging species', originally introduced by Marshall Ward to mark a host plant which was susceptible to distinct physiological strains of fungi from two further hosts which would not inter-infect. The bridging species would 'educate' the strains to infect their mutual hosts. A simpler explanation of Marshall Ward's results seems to lie in the large number of physiological forms which are now known to exist.

The interaction of two or more fungi upon one another has a profound influence on plant pathology. A rotting log provides material for a succession of fungi, one after another, and each with its own particular taste for wood at a certain stage of decomposition. Similarly, a wheat plant normally resistant to Puccinia glumarum becomes susceptible to that fungus if attacked also by bunt (Tilletia Caries). More severe attacks of citrus trees follow infection by Diplodia natalensis and Colletotrichum gloeosporioides together than is the case with either organism alone ${ }^{5}$. 
Two organisms may also act in antagonism to one another. Mr. Brooks's experiments on various spccies of Stereum show that oak wood attacked by S. hirsutum is not a suitable habitat for the more harmful S. purpureum. Fawcett and $\mathrm{Lee}^{6}$ could not obtain any effect on the walnut tree by inoculating it with two parasitic fungi, each of proved pathogenicity. Millard and Taylor ${ }^{7}$ also found that the organism causing common scab of potatoes lives in antagonism with a harmless species. The latter can be stimulated by the addition of organic matter to the soil, thus controlling the disease. Weindling ${ }^{8}$ found that Trichoderma lignorum, a saprophytic fungus, produces a substance which is toxic to the hyphæ of Rhizoctonia solani, and, indeed, the depredations of the latter can be curtailed if spores of $T$. lignorum are added to the soil. The old saying "Set a thief to catch a thief" seems to be justified even in the realm of plant pathology.

Many disorders of plants appear for which no definite causal agent can be demonstrated. Certain crops, for example, do not make good growth if the element boron is absent from the soil. Heartrot of sugar beet and mangolds seems to be due to such lack. Manganese deficiency is responsible for grey leaf or grey-speck of oats, whilst insufficient sulphur produces a serious disease of tea bushes in Nyasaland ${ }^{9}$. Several diseases of apples during storage are due to inordinately large amounts of carbon dioxide in the atmosphere. Brown heart is such a disease which ean be overcome entirely by proper ventilation ${ }^{10}$. Injury by frost can also produce symptoms which are similar to those caused by some fungi. Canker of the larch tree, for example, may be caused either by frost, or by the depredations of Dasyscypha ${ }^{11}$, both of which, in all probability, kill groups of active cambium cells.

Many of the researches outlined in Mr. Brooks's address have added to general botanical knowledge. It is often necessary for the pathologist to study a new phase of plant physiology, and alternatively, the physiologist can supply knowledge which is useful to the pathologist. The address was pre-eminently what we have come to desire of a sectional president-a point of view, emanating from his own specialist knowledge, and linking up with other branches comprised within his Section; the orientation of scattered facts into one harmonious whole.

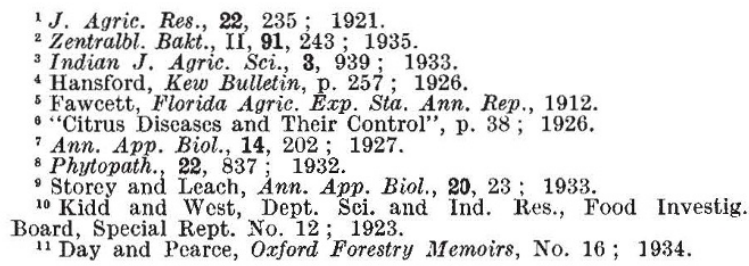

${ }_{11}$ Day and Pearce, Oxford Forestry Memoirs, No. 16; 1934.

\section{Speed*}

\section{By Prof. B. Melvill Jones}

$\mathrm{T}$ $\mathrm{HE}$ factors which have limited speed in the past can be grouped under two main heads, which may be roughly described by the words Track and Power. To move rapidly over the ground a smooth track is necessary in order to prevent the vehicle from bumping itself to pieces and from overturning, while power is required to overcome the internal friction of the mechanism and the head resistance which must always oppose motion, until we can arrange to do our travelling entirely outside the earth's atmosphere. These two factors, track and power, have alternately imposed limits on the speed of travel, one coming into operation whenever the other was temporarily removed.

The power to fly through the air at a height sufficient to be clear of the irregular air flow near the ground has at last disposed of the track

* From a Friday evening discourse delivered before the Royal Institution on March 22 problem as a factor limiting speed. For although the aeroplane has to lay its own track, in the sense that it has to expend power in doing something to the air in order to keep itself from falling, that power becomes continually less the greater the speed of flight and, of itself, is incapable of placing any limit on speed.

In the early days of flying, we were unable to separate the power essentially required for support-for track laying as we may describe itfrom the power required merely to drag the aeroplane through the air. That this can now be done is due to the work of Prof. L. Prandtl, which was itself founded on some earlier work of that amazing mechanical genius, Dr. F. W. Lanchester. Looking back from our present point of view, Lanchester's insight into this very difficult problem seems almost miraculous, but he did not put his ideas into a form which appealed to the conventional man of science, and it was not until 